Lampiao et al., Afr J Tradit Complement Altern Med., (2018) 15 (3): 27-30

https://doi.org/10.21010/ajtcam.v15i3.3

\title{
EVALUATION OF THE HYPOGLYCAEMIC POTENTIAL OF KIGELIA AFRICANA FRUIT POWDER BEING SOLD IN MALAWIAN RETAIL PHARMACIES
}

\author{
Fanuel Lampiao $^{1 *}$, Samson Kafukiza ${ }^{2}$, Denise Msowoya ${ }^{2}$, Thokozire Phiri ${ }^{2}$, Lina Wyson ${ }^{2}$, \\ Louisa Alfazema ${ }^{2}$
}

${ }^{1}$ Africa Centre of Excellence in Public Health and Herbal Medicine, College of Medicine, P/Bag 360, Blantyre, Malawi; ${ }^{2}$ Pharmacy Department, College of Medicine, P/Bag 360, Blantyre, Malawi.

*Corresponding Author's E-mail: flampiao@medcol.mw

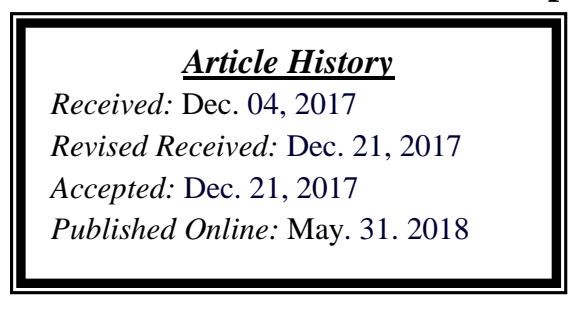

Abstract

Background: Kigelia africana fruit powder is being sold in Malawian retail pharmacies for the purported purpose of lowering blood sugar in diabetic patients when there is scant data on its hypoglycaemic activity. This study was aimed at evaluating the hypoglycaemic potential of the Kigelia africana fruit powder being sold in Malawian retail pharmacies.

Materials and Methods: Hyperglycaemia was induced in rats via intra-peritoneal injection of dexamethasone. Albino rats were randomly allocated into five different groups of eight rats each. Group 1 consisted of non-hyperglycaemic rats receiving no treatment, group 2 consisted of hyperglycaemic rats receiving no treatment, group 3 consisted of hyperglycaemic rats receiving $25 \mathrm{mg} / \mathrm{kg}$ of metformin, group 4 consisted of hyperglycaemic rats receiving $0.5 \mathrm{~mL}$ of Kigelia africana fruit powder filtered solution, and group 5 consisted of hyperglycaemic rats receiving $1 \mathrm{~mL}$ of Kigelia africana fruit powder solution.

Results: The Kigelia africana fruit powder filtered solution administered to hyperglycaemic albino rats significantly lowered the sugar level which was comparable to the reduction caused by the pharmacological drug, metformin.

Conclusions: Kigelia africana fruit powder has the potential of lowering glucose levels in white albino rats.

Key words: Kigelia africana, hyperglycaemia, diabetes, herbal medicine

\section{Introduction}

Over the past four decades, prevalence of diabetes in Malawi has increased from 1\% or less to $5.6 \%$ in 2014 to become a major public health problem and one of the leading causes of death (Msyamboza et al., 2014). Diabetes was the cause of $1.23 \%$ of all deaths in Malawi in the year 2014 (Msyamboza et al., 2014). Hence there has been an increase in herbal remedies with alleged anti-diabetic activity being sold in the local markets whose therapeutic effects have not been investigated.

Kigelia africana fruit powder is one of the plants being used as an anti-diabetic remedy. It has various plant parts such as flowers, leaves and fruit which have long been used by traditional healers to treat a wide range of ailments such as fungal infections, boils, diabetes, pneumonia and many others (Saini et al., 2009) The Kigelia africana tree is widely distributed in South, Central and West Africa, and hot regions of Malawi.

The different parts of Kigelia africana tree have been studied for varied pharmacological effects. A study has reported that the fruit of Kigelia africana has many significant pharmacological properties which include antifungal, antibacterial, antineoplastic, antiulcer and anti-inflammation (Atawodi and Olowoniyi, 2015).

Some of the plant's parts, flowers and leaves, have been evaluated for their anti-diabetic activity through analysis of their hypoglycaemic effects (Kumar et al., 2012; Dhriti et al., 2014). The Kigelia africana fruit is the plant part most commonly used as a diabetic herbal remedy and yet there is limited research into its hypoglycaemic effect when the powdered fruit is used as the sole active ingredient. 
The fruit has been reported to contain a number of constituents, namely; irridoids, phenylpropanoid derivatives, naphthoquinones, flavonoids, glycosides, flavonoid glycosides, alkaloids, terpenoids, tannins, saponins and reducing sugars (Gabriel and Olubunmi, 2009).

Kigelia africana fruit powder is being sold in Malawian retail pharmacies and indicated for diabetes despite the fact that there is no scientific evidence on its antidiabetic or hypoglycaemic activity. The Kigelia africana powder sold in pharmacies has no indication of manufacturing and expiry dates. This study was aimed at investigating the antihyperglycaemic properties of Kigelia africana fruit powder in a hyperglycaemic albino rat model.

\section{Materials and Methods Preparation of Plant extract}

Ten grams of Kigelia Africana powder bought from a retail pharmacy was mixed with up to $100 \mathrm{~mL}$ of water and heated slightly. The resulting mixture was filtered and the solution administered to different groups of rats at low dose $(0.5 \mathrm{~mL})$ and high dose $(1 \mathrm{~mL})$.

\section{Animals and treatment}

Ethical approval for the study was granted by the College of Medicine Research and Ethic Committee (COMREC). Forty (40) male albino rats, aged 8-10 weeks were given free access to food (standard rat chow) and water unless when fasted prior to fasting blood sugar (FBS) sample collection. They were subjected to standard atmospheric conditions with a twelve hours light/dark cycle. Animals were randomly divided into five groups $(\mathrm{n}=8)$ and treated as follows; (a) Health controls, (b) Hyperglycaemic control animals receiving normal saline at $0.5 \mathrm{~mL} / 100 \mathrm{~g}$ body weight daily, (c) Hyperglycaemic rats receiving $25 \mathrm{mg} / \mathrm{kg}$ of metformin, (d) Hyperglycaemic rats receiving low dose of Kigelia africana of $0.5 \mathrm{~mL}$, (e) Hyperglycaemic rats receiving high dose of Kigelia Africana of $1 \mathrm{~mL}$. In order to collect blood from the rats, the tail vein was punctured using a sharp sterile needle. The drop of blood sample was smeared on the ACCUCHECK glucose stick of the ACCUCHECK glucometer to give a blood glucose reading. The maintenance and care of experimental animals throughout the study complied with National Institutes of Health guidelines for the humane use of laboratory animals. The dosage indicated on the samples of Kigelia africana powder sold in pharmacies is two tea spoons of the powder in a cup of tea.

\section{Induction of hyperglycaemia}

Hyperglycaemia was induced by intra-peritoneal injection of each rat with $4 \mathrm{mg} / \mathrm{kg}$ of dexamethasone once daily for six consecutive days (Grover, et al., 2011). Dexamethasone induced hyperglycaemia by increasing hepatic synthesis of glucose and decreasing the sensitivity of insulin on cells (Roy-Fleming, 2014).

\section{Data analysis}

The results were analyzed on the Prism 7 statistical program (Graph Pad, San Diego, CA, USA). All data are expressed as mean \pm SEM. One-way ANOVA (with Bonferroni post hoc test if $P<0.05$ ) was used for statistical analysis. Differences were regarded statistically significant if $P<0.05$.

\section{Results}

From figure 1, our results have shown that dexamethasone induced hyperglycaemia in albino rats as demonstrated by statistically significantly high levels of glucose in the hyperglycemic control group when compared to the health control group $(149 \pm 5.13$ Vs. $101.8 \pm 2.95, P<0.05)$. When the hyperglycaemic rats were treated with metformin, we observed a statistically significant reduction of glucose levels $(149 \pm 5.13$ Vs. $104 \pm 2.02, P<0.05)$. Similarly, low and high dosage of Kigelia africana significantly lowered hyperglycaemia in albino rats (149 \pm 5.13 Vs. $109.6 \pm ; 106.3 \pm 2.18$, respectively, $P$ $<0.05)$. No statistically significant differences were observed among the metformin, low and high dose Kigelia treated groups when compared to the health control. 


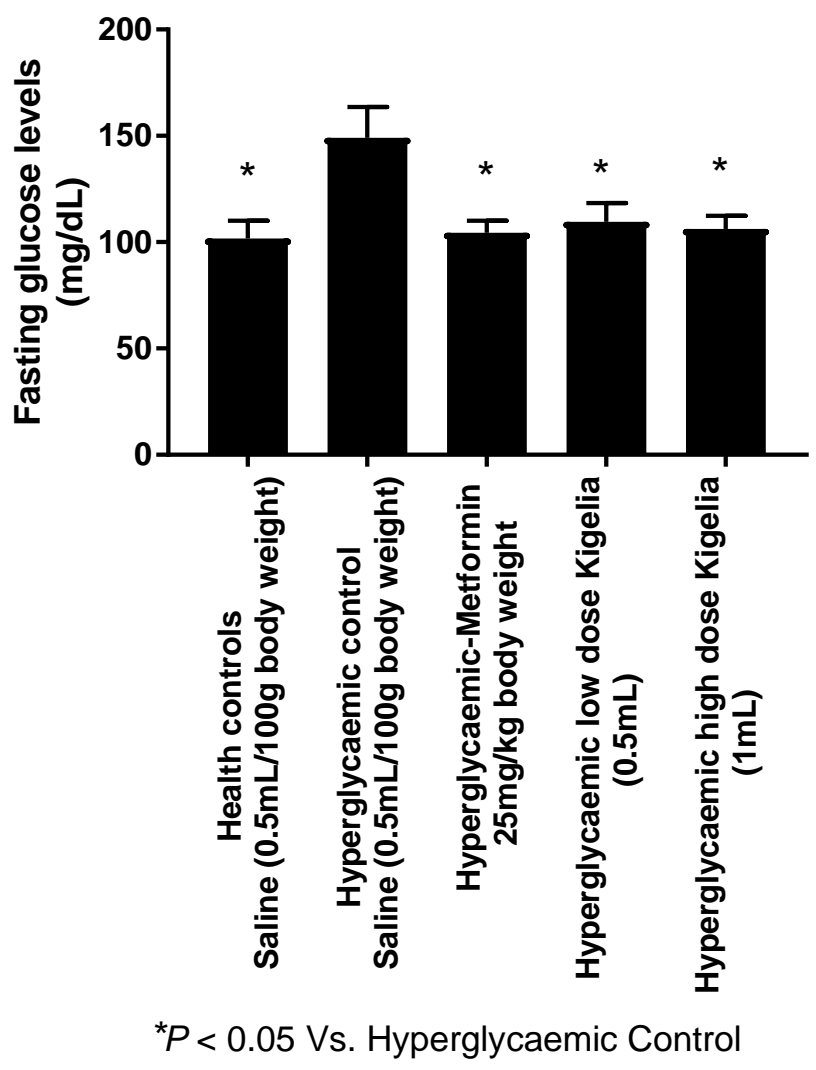

Figure 1: Fasting blood glucose levels in albino rats given different treatments

\section{Discussion}

Some pharmacological agents have an effect on glucose homeostasis in the body which may result in either hypoor hyperglycaemia (Rehman et al., 2011). In this study, hyperglycaemia was induced in the white albino rats via intraperitoneal injection of dexamethasone for six days. This is in agreement with a study conducted by Bhat et al (2015), in which dexamethasone also elevated blood sugar levels in albino rats (Bhat et al., 2015). In their study they reported fasting blood glucose levels in albino rats of around $216 \mathrm{mg} / \mathrm{dL}$ which is higher than the average levels reported in this current study of $149 \mathrm{mg} / \mathrm{dL}$. This could be due to several reasons such as differences in the dosage of dexamethasone used or differences in the ages of the rats used in the experimentation. In this study we used a dosage of $4 \mathrm{mg} / \mathrm{kg} \mathrm{while} \mathrm{they} \mathrm{used} \mathrm{a}$ higher dosage of $8 \mathrm{mg} / \mathrm{kg}$. The albino rats used in this study were aged between 8-10 weeks while they did not report the ages of the rats used in their study.

The findings of this study indicate that the solution of Kigelia africana fruit powder has the ability to lower fasting blood glucose levels of hyperglycaemic albino rats. Its potential to lower hyperglycaemia is similar to that of antihyperglycaemic drugs such as metformin. In a previous study, the phyotochemical analysis of Kigelia africana fruit extract showed the presence of alkaloids, saponins, tannins, glycosides, steroids, and flavonoids (Muyenga 2015). Part of the hypoglycaemic activity of Kigelia africana leaves has been attributed to their alpha amylase inhibitory activity and since most of the phytochemicals present in leaves are also found in fruit, the same constituents might be responsible for the blood glucose lowering activity in the fruit powder (Dhriti etbal., 2014). In conclusion, Kigelia africana fruit powder has the ability to lower fasting blood glucose levels of hyperglycaemic rats. Future studies will indicate the mechanism through which the extract of Kigelia africana fruit lowers hyperglycaemia.

Conflict of Interest: The authors declare that there is no conflict of interest. 


\section{References}

1. Atawodi, S. E.O., Olowoniyi, O. D. (2015). Pharmacological and therapeutic activities of Kigelia africana. Annual Rresearch \& Review in Biology 5: 1-17.

2. Bhat, G.M.N., Nayak, N., Vinodraj, K., Chandralekha, N., Mathai, P., Cherian, J. (2015). Comparison of the efficacy of Cardamom (Elettaria cardamomum) with pioglitazone and dexamethasone-induced hepatic steatosis, dyslipidemia, and hyperglycaemia in albino rats. Journal of Advanced Pharmaceutical Technology and Research 6: 136-140.

3. Dhriti, V., Chowdary, P. V., Rahul, J., Vishank, G., Shivaji, B. (2014). Free radical scavenging and antidiabetic activity of Kigelia Pinnata. World Journal of Pharmacy and Pharmaceutical Sciences 3: 1249-1262.

4. Gabriel, O. A., Olubunmi, A. (2009). Comprehensive scientific demystifiction of Kigelia Africana: A review. African Journal of Pure and Applied Chemistry 3: 158-164.

5. Grover, N., Bafna, P., Rana, A. (2011). Diabetes and methods to induce experimental diabetes. International Journal of Pharmacy and Biological Sciences 1: 414-419.

6. Kumar, S., Kumar, V., Prakash, O. (2012). Antidiabetic and hypolipidemic activities of Kigelia pinnata flowers extract in streptozotocin induced diabetic rats. Asian Pacific Journal of Tropical Biomedicine 2: 543-546.

7. Msyamboza, K. P., Mvula, C. J., Kathyola, D. (2014). Prevalence and correlates of diabetes mellitus in Malawi: population based national NCD STEPS survey. BMC Endocrine Disorders 14: 41-46.

8. Muyenga, T. (2015). The effect of Kigelia africana fruit extract on blood glucose in diabetes induced mice. MSc Dissertation, University of Zambia.

9. Rehman, A., Setter, S.M., Vue, M.H. (2011). Drug-induced glucose alterations part 2: drug-induced hyperglycaemia. Diabetes Spectrum 24: 234-238.

10. Roy-Fleming, A. (2014). How glucocorticoids effect blood sugar. [Online] Available at: www.diabete.qc.ca/en/understand-diabetes/practice/special-situations/how-glucocorticoids-effect-blood-sugar [Accessed September 2016].

11. Saini, S., Kaur, H., Verma, B., Singh. S.K. (2009). Kigelia Africana - An overview. Natural Product Radiance 8: 190-197. 